\title{
Different responses of photosystem and antioxidant defense system to three environmental stresses in wheat seedlings
}

\author{
N. WU*, H.T. MAO*, M.Y. CHEN*, J. DONG*, M. YUAN*, Z.W. ZHANG**, S. YUAN**, \\ H.Y. ZHANG ${ }^{*}$, and Y.E. CHEN ${ }^{*},+$ \\ College of Life Sciences, Sichuan Agricultural University, 625014 Ya'an, China* \\ College of Resources Science and Technology, Sichuan Agricultural University, 611130 Chengdu, China**
}

\begin{abstract}
To investigate the adaptive mechanism of wheat under high light, osmotic stress, and salt stress, redox regulation, and photosynthesis were compared. Under high light, the activities of antioxidant enzymes, except for catalase, significantly increased and then decreased after 1 and $3 \mathrm{~h}$, respectively. Under osmotic stress, antioxidant enzyme activities significantly increased and subsequently declined. Except for superoxide dismutase, salt stress induced a significant increase in all the antioxidant enzyme activities. A significant decrease of D1 protein by high light and osmotic stress, strong photophosphorylation of D1 and D2 under high light and salt stress were observed, while all the stresses induced upregulation of PsbS protein. Eight stress-associated genes (TaMYB73, TaABC1, TaOPR1, TaASR1, TaWRKY44, TaWRKY2, TaWRKY19, and TaCIPK29) showed different expression levels under all the stresses. We conclude that the wheat plant adopted various strategies by regulating the antioxidant system, expression of stress-responsive genes, and photosystems under different abiotic stresses.
\end{abstract}

Additional key words: chlorophyll fluorescence; gene expression; reactive oxygen species; Triticum aestivum.

\section{Introduction}

Wheat is one of the main food security crops, and it serves as a basic staple food to meet the daily calorific and protein needs of most people in the world. However, the increase in the frequency and magnitude of environmental stresses during the growth and development of wheat is predicted to be the main factor concerning the loss of cereal productivity (Barnabás et al. 2008, Farooq et al. 2011). Some studies from wheat and rice indicated that environmental stresses usually affect the growth and development of crops at almost all developmental phases (Shah et al. 2011, Cossani and Reynolds 2012). In addition, abiotic stress factors can influence the production of secondary metabolites in higher plants (Ramakrishna and Ravishankar 2011, Mbarki et al. 2018).

Among abiotic stresses, osmotic stress is thought to be one of significant environmental stresses that affects plant growth and development (Chaves 1991). Previous studies showed that drought led to the stomatal closure and decrease in photosynthetic efficiency (Loggini et al. 1999, Grassi and Magnani 2005). Salinity is another abiotic stress, which affects crop productivity, photosynthesis, stomatal closure, and causes oxidative stress (Flowers 2004, Chen et al. 2018). Besides, high light often results in photoinhibition and decrease in photosynthetic activity (Powles 1984, Chen et al. 2017). It is reported that the reaction center of PSII is the key site, where damage caused by various environmental stresses occurs in the photosynthetic apparatus of plants (Adir et al. 2003, Murata et al. 2007). Although our previous studies indicated that PSII proteins showed different changes under different environmental stresses in different plant species (Chen et al. 2016a, 2017), it is still unknown how PSII proteins response to different environmental stresses in the same plants.

Reactive oxygen species (ROS) were found to be generated during photosynthesis process (Mehler 1951). Excessive accumulation of ROS, such as superoxide radical $\left(\mathrm{O}_{2}{ }^{-}\right)$and hydrogen peroxide $\left(\mathrm{H}_{2} \mathrm{O}_{2}\right)$, can lead to severe

Received 25 August 2019, accepted 18 November 2019.

${ }^{+}$Corresponding author; e-mail: anty9826@163.com

Abbreviations: APX - ascorbate peroxidase; CAT - catalase; Chl - chlorophyll; $\mathrm{F}_{\mathrm{v}} / \mathrm{F}_{\mathrm{m}}$ - maximal quantum yield of PSII photochemistry; GPX - glutathione peroxidase; GR - glutathione reductase; NPQ - nonphotochemical quenching; POD - peroxidase; $\mathrm{q}_{\mathrm{N}}-$ nonphotochemical quenching coefficient; $\mathrm{q}_{\mathrm{p}}$ - photochemical quenching coefficient; ROS - reactive oxygen species; SOD - superoxide dismutase; TaABC1 - ABC1 protein kinase; TaASR1 - abscisic stress-ripening protein 1; TaCIPK29 - CBL-interacting protein kinase 29; TaMYB73 - MYB transcription factor 73; TaOPR1 - 12-oxophytodienoate reductase 1; TaWRKY2 - WRKY DNA-binding protein 2; TaWRKY19 - WRKY DNA-binding protein 19; TaWRKY44 - WRKY transcription factor 44; $\Phi_{\mathrm{NA}}$ - reduction status of PSI acceptor side; $\Phi_{\mathrm{ND}}-$ oxidation status of PSI donor side; $\Phi_{\mathrm{PSI}(\mathrm{II})}$ - photochemical quantum yield of PSI(II).

Acknowledgments: This work was financially supported by Sichuan Province Academic and Technical Leaders Fund, Xichang Municipal Science and Technology Program (18JSYJ09), and Sichuan Science and Technology Program (2018HH0129). We are especially grateful to Jian Li (Ohio University) for the language editing of the manuscript. 
oxidative damage in plants, especially under environmental stresses (Mittler 2002). The accumulation of ROS can damage cell membranes and other macromolecules including photosynthetic pigments, proteins, lipids, and nucleic acids (Gill and Tuteja 2010). Our recent studies also showed that high light, drought, and salt stress resulted in the obvious ROS accumulation in wheat, maize, and Arabidopsis (Chen et al. 2016a, 2017, 2018). To alleviate the toxic effects of ROS on photosystems under environmental stresses, photoprotection mechanisms are usually activated through the nonphotochemical quenching (NPQ), by which the excessive light energy absorbed by the pigmentbinding proteins is dissipated as heat (Niyogi 2000). In addition, different plants also have developed enzymatic and nonenzymatic antioxidant system to alleviate oxidative stress resulting from environmental reasons (Mittler et al. 2004). Many previous studies indicated that the activities of antioxidative enzymes and nonenzymatic antioxidants showed different changes in different plants under environmental stresses (Chen et al. 2016a, 2017, 2018). Therefore, it is very important to investigate the different responses of the antioxidant system to different environmental stresses in the same plant.

In the present study, photosynthesis and antioxidant system of wheat seedling under three environmental stresses (osmotic stress, salt stress, and high light) were investigated by comparing the differences in photosynthetic efficiency, gas-exchange parameters, the activities of antioxidative enzymes, ROS accumulation, the occurrence of photosynthetic proteins, and phosphorylation of PSII proteins. The major aim of this work was to explore the responses of the same plant to different environmental stresses in term of oxidative stress and redox regulations. Our results showed that different responses of the antioxidant system and the levels and phosphorylation of PSII proteins are involved in the oxidative damage and redox regulation in wheat under environmental stresses.

\section{Materials and methods}

Plant materials and stress treatment: Sterilized wheat (Triticum aestivum L., cv. CN19) seeds were sown in Petri dishes and germinated for $72 \mathrm{~h}$ at the room temperature in the dark. Then, the seedlings were cultured with $1 / 2$ Hoagland's solution in the greenhouse $\left(25 / 20^{\circ} \mathrm{C}\right.$ day/ night temperature; a photoperiod of 16/8-h day/night; PPFD of $250 \mu \mathrm{mol} \mathrm{m} \mathrm{m}^{-2} \mathrm{~s}^{-1} ; 75-85 \%$ relative humidity). After two weeks, wheat seedlings (third-leaf stage) were subjected to three environmental stresses (Table 1S, supplement). For high light, wheat seedlings were exposed to $1,500 \mu \mathrm{mol}$ (photon) $\mathrm{m}^{-2} \mathrm{~s}^{-1}$ for $1 \mathrm{~h}$ or $3 \mathrm{~h}$. Osmotic stress was imposed by submerging wheat roots into $1 / 2$ strength Hoagland solution containing $20 \%(\mathrm{w} / \mathrm{v})$ polyethylene glycol (PEG)-6000 with an osmotic potential of $-0.5 \mathrm{MPa}$ for $1 \mathrm{~d}$ or $3 \mathrm{~d}$. For salt stress, plants were treated with $0.3 \mathrm{M} \mathrm{NaCl}$ for $1 \mathrm{~d}$ or $3 \mathrm{~d}$. Control plants were cultured in $1 / 2$ Hoagland solution. After different treatments, physiological and biochemical parameters were determined.

Chlorophyll (Chl) contents and leaf water status: Wheat leaves $(0.5 \mathrm{~g})$ were homogenized in $80 \%(\mathrm{v} / \mathrm{v})$ acetone, and contents of $\mathrm{Chl}$ were determined by measuring absorbance at 663 and $645 \mathrm{~nm}$, using a UV-visible spectrophotometer (Hitachi-U2000, Tokyo, Japan). Contents of Chl $a$ and $b$ were calculated according to Arnon (1949).

Leaf water status in the fully developed leaves was estimated by measuring the relative water content (RWC). RWC was calculated following the formula: RWC = (fresh mass - dry mass)/(turgid mass - dry mass) $\times 100 \%$. The turgid mass was obtained after putting the leaves into distilled water in darkness at $4^{\circ} \mathrm{C}$ overnight, until they reached a constant mass. Dry mass was determined through keeping the turgid leaf in an oven with $85^{\circ} \mathrm{C}$ for $24 \mathrm{~h}$.

Total protein content and osmotic regulators: The measurement of the total proteins was performed according to the previous method using a UV-visible spectrophotometer (Hitachi-U2000, Tokyo, Japan) (Lowry et al. 1951). Soluble sugar and proline in the leaves were extracted using $80 \%(\mathrm{v} / \mathrm{v})$ ethanol solution and $30 \%(\mathrm{w} / \mathrm{v})$ sulfosalicylic acid, respectively. Then, contents of soluble sugar and proline were measured as described previously by Thomas (1977) and Bates et al. (1973), respectively.

Measurements of malondialdehyde and electrolyte leakage: The extraction of malondialdehyde (MDA) in wheat leaves was performed using thiobarbituric acid (TBA) solution according to the method of Chen et al. (2015). After centrifugation, the absorbance of the supernatant was monitored at $532 \mathrm{~nm}$ and corrected for nonspecific turbidity by subtracting the absorbance at $600 \mathrm{~nm}$. Electrolyte leakage (EL) was determined by using a conductivity meter (DDSJ-308A, Shanghai Precision Instruments Co. Ltd., Shanghai, China) according to the method of Chen et al. (2015). The relative EL was obtained according to the ratio of the initial conductivity to the absolute conductivity.

Analysis of Chl fluorescence and gas exchange: $\mathrm{Chl}$ fluorescence of leaves was determined with an Imaging PAM M-Series Chl fluorescence system (Heinz Walz Instruments, Effeltrich, Germany) at room temperature according to the manufacturer's instructions. All samples were dark-adapted for $30 \mathrm{~min}$ prior to the fluorescence measurements. Values of $\mathrm{F}_{0}$ (minimum fluorescence yield) and $\mathrm{F}_{\mathrm{m}}$ (maximum fluorescence yield) were averaged to improve the signal-to-noise ratio. An irradiance of $180 \mu \mathrm{mol}$ (photon) $\mathrm{m}^{-2} \mathrm{~s}^{-1}$ was given as actinic light. The maximal quantum yield of PSII photochemistry $\left(F_{v} / F_{m}\right)$, the photochemical quenching coefficient $\left(q_{p}\right)$, the effective quantum yield $\left(\Phi_{\mathrm{PSII}}\right)$, and the nonphotochemical quenching coefficient $\left(\mathrm{q}_{\mathrm{N}}\right)$ were calculated according to the method of Maxwell and Johnson (2000). Image data acquired were normalized to a false color scale in each measurement.

A dual PAM-100 fluorometer (Heinz Walz Instruments, Effeltrich, Germany) with a ChlF unit and P700 dual wavelength $(830 / 875 \mathrm{~nm})$ unit was applied for the measurement of PSI photochemistry in seedling leaves 
according to Klughammer and Schreiber (1994). Oxidation status of PSI donor side $\left(\Phi_{\mathrm{ND}}\right)$, reduction status of PSI acceptor side $\left(\Phi_{\mathrm{NA}}\right)$, and the effective quantum yield of PSI $\left(\Phi_{\text {PSI }}\right)$ were obtained according to the previous method (Klughammer and Schreiber 1994).

The kinetics of nonphotochemical quenching (NPQ) and state transition measurements in whole leaves were performed with a dual PAM-100 fluorometer as the previous method (Pietrzykowska et al. 2014). Plants were dark-adapted for $1 \mathrm{~h}$ before the measurements. $\mathrm{F}_{\mathrm{m}}$ value in State I $\left(\mathrm{F}_{\mathrm{m}}{ }^{\prime}\right)$ and State II $\left(\mathrm{F}_{\mathrm{m}}{ }^{\prime \prime}\right)$ were determined at the end of each state transition cycle by the application of the saturating light pulse.

The GSF-3000 photosynthetic system (Heinz Walz Instruments, Effeltrich, Germany) was applied to determine the net photosynthetic rate $\left(P_{\mathrm{N}}\right)$, stomatal conductance $\left(g_{\mathrm{s}}\right)$, intercellular carbon dioxide concentration $\left(C_{\mathrm{i}}\right)$, and transpiration rate $(E)$ under PPFD of $1,500 \mu \mathrm{mol} \mathrm{m}{ }^{-2} \mathrm{~s}^{-1}$. Air humidity in the leaf chamber was about $70 \%$. The $\mathrm{CO}_{2}$ concentration of $360 \mu \mathrm{mol} \mathrm{mol}{ }^{-1}$ was applied for analysis of $\mathrm{CO}_{2}$ assimilation rate at room temperature.

Assay of reactive oxygen species (ROS) and tissue staining: Superoxide $\left(\mathrm{O}_{2}^{-}\right)$and hydrogen peroxide $\left(\mathrm{H}_{2} \mathrm{O}_{2}\right)$ of leaves were visualized using nitroblue tetrazolium (NBT) and 3,3-diaminobenzidine (DAB), respectively. The third leaf was cut at the leaf base and immersed in $0.5 \mathrm{mg}(\mathrm{NBT}) \mathrm{mL}^{-1}$ or $2 \mathrm{mg}(\mathrm{DAB}) \mathrm{mL}^{-1}$ solution for $2-8 \mathrm{~h}$ with vacuum infiltration in the dark. Then, the stained leaves were decolorized in $95 \%$ ethanol for $0.5-2 \mathrm{~h}$ in boiling water. Further, contents of $\mathrm{O}_{2}^{-{ }^{-}}$and $\mathrm{H}_{2} \mathrm{O}_{2}$ in samples were determined, following the previous methods (Okuda et al. 1991, Verma and Mishra 2005). For the analysis of cell death, the third leaf was stained by trypan blue $\left(1.25 \mathrm{mg} \mathrm{mL}^{-1}\right.$, Sigma) following the method of van Wees (2008).

Antioxidant systems: The enzymes were extracted from $0.5 \mathrm{~g}$ of fresh leaf tissues using a chilled mortar and pestle with $5 \mathrm{~mL}$ ice-cold $25 \mathrm{mM}$ HEPES buffer $(\mathrm{pH} 7.8)$ containing $0.2 \mathrm{mM}$ ethylenediaminetetraacetic acid (EDTA), $2 \mathrm{mM}$ ascorbate, and $2 \%(\mathrm{w} / \mathrm{v})$ polyvinylpyrrolidone (PPVP) at $4{ }^{\circ} \mathrm{C}$. The supernatants were collected and applied for the measurements of enzymes after centrifugation $\left(12,000 \times \mathrm{g}, 20 \mathrm{~min}, 4^{\circ} \mathrm{C}\right)$. The reaction solution of superoxide dismutase (SOD, EC 1.15.1.1) assay ( $3 \mathrm{~mL}$ ) contained phosphate buffer (50 mM, pH 7.8), EDTA-Na $(0.1 \mathrm{mM})$, L-methionine $(12 \mathrm{mM})$, riboflavin (2 $\mu \mathrm{M})$, nitrotetrazolium blue chloride $(75 \mu \mathrm{M})$, crude enzyme extract $(100 \mu \mathrm{L})$, and riboflavin $(20 \mu \mathrm{M})$. The $50 \%$ inhibition in the activity of nitroblue tetrazolium caused by the reduction at $560 \mathrm{~nm}$ was obtained as one unit of SOD activity (Giannopolitis and Ries 1977). Peroxidase (POD, EC 1.11.1.7) activity was determined by measuring the oxidation of guaiacol $\left(\mathrm{A}_{470}\right)$ in the reaction mixture $(3 \mathrm{~mL})$, containing phosphate buffer (2.9 mL, $50 \mathrm{mM}, \mathrm{pH} 7.0)$, guaiacol $(50 \mu \mathrm{L}, 10 \mathrm{mM}), \mathrm{H}_{2} \mathrm{O}_{2}$ $(10 \mu \mathrm{L}, 40 \mathrm{mM})$, and crude enzyme extract $(40 \mu \mathrm{L})$. Catalase (CAT, EC 1.11.1.6) activity was detected by determining the initial rate of decomposition of $\mathrm{H}_{2} \mathrm{O}_{2}$ at $240 \mathrm{~nm}$ in the reaction mixture $(3 \mathrm{~mL})$, containing phosphate buffer (50 mM, pH 7.0), $\mathrm{H}_{2} \mathrm{O}_{2}(20 \mathrm{mM})$, and crude enzyme extract $(100 \mu \mathrm{L})($ Beers and Sizer 1952, Havir and McHale 1987). CAT activity was calculated using the molar extinction coefficient of $\mathrm{H}_{2} \mathrm{O}_{2}\left(40 \mathrm{mM}^{-1} \mathrm{~cm}^{-1}\right)$ and expressed as $\mu \mathrm{mol}\left(\mathrm{H}_{2} \mathrm{O}_{2}\right) \mathrm{min}^{-1} \mathrm{mg}^{-1}(\mathrm{DM})$. The assay of ascorbate peroxidase (APX, EC 1.11.1.11) was performed by adding the crude enzyme extract $(100 \mu \mathrm{L})$ into the medium $(3 \mathrm{~mL})$ which contained HEPES-KOH (50 mM, pH 7.6), ethylenediaminetetraacetic acid $(0.1 \mathrm{mM}), \mathrm{H}_{2} \mathrm{O}_{2}(0.2 \mathrm{mM})$, and ascorbate (AsA, $0.5 \mathrm{mM}$ ). Then, the decrease of AsA content at $290 \mathrm{~nm}$ was used to calculate APX activity (Nakano and Asada 1981). APX activity was expressed as $\mu \mathrm{mol}(\mathrm{AsA}) \mathrm{min}^{-1} \mathrm{~g}^{-1}(\mathrm{DM})$. Glutathione peroxidase (GPX, EC 1.11.1.9) activity was determined by monitoring the formation process of guaiacol dehydrogenation product at $340 \mathrm{~nm}$ in a reaction mixture $(3 \mathrm{~mL})$, containing phosphate buffer (100 mM, pH 7.0), GSH (4 mM), NADPH (0.2 mM), GR $(0.05 \mathrm{U})$ and $100 \mu \mathrm{L}$ of the extract (Rico et al. 2013). The GPX activity was calculated using using the extinction coefficient $6.62 \mathrm{mM}^{-1} \mathrm{~cm}^{-1}$ and was expressed as $\mu \mathrm{mol}\left(\mathrm{NADP}^{+}\right) \mathrm{min}^{-1} \mathrm{~g}^{-1}(\mathrm{DM})$. Glutathione reductase (GR, EC 1.6.4.2) activity was assayed by measuring the oxidation of NADPH at $340 \mathrm{~nm}$ in the reaction mixture ( $3 \mathrm{~mL})$ that contained Tris- $\mathrm{HCl}$ buffer $(0.25 \mathrm{M}, \mathrm{pH} 8.4)$, GSSG (4 mM), NADPH (1.5 mM), and 5,5'-dithiobis2-nitrobenzoic acid (2 mM) (Foyer and Halliwell 1976). One unit (U) of GR was measured in terms of NADPH oxidized $\mathrm{min}^{-1}$ with a molar absorption coefficient of $6.2 \mathrm{mM}^{-1} \mathrm{~cm}^{-1}$.

Contents of reduced ascorbic acid (AsA) and dehydroascorbate (DHA) were analyzed by a high-performance liquid chromatography (HPLC) (Xu et al. 2012). Approximately $0.2 \mathrm{~g}$ of wheat leaves were homogenized by the addition of $2 \mathrm{~mL}$ of $5 \%(\mathrm{w} / \mathrm{v})$ metaphosphoric acid in ice bath. To extract AsA and DHA, the mixture was shaken at $4^{\circ} \mathrm{C}$ for $30 \mathrm{~min}$ and then the extract was centrifuged at $8,000 \times g$ for $15 \mathrm{~min}$. The extract was measured by HPLC, Agilent 1260 system using a C18-ODS $(3.5 \mu \mathrm{m} \times 150 \mathrm{~mm} \times$ $4.6 \mathrm{~mm}$ ) column (Agilent, USA) and a UV/VIS detector. The run time of $10 \mathrm{~min}$ was chosen when the mobile phase was a phosphoric acid/methanol gradient. The absorbance was scanned at $254 \mathrm{~nm}$. The measurement of contents of reduced glutathione (GSH) and oxidized glutathione (GSSG) were performed following the method of Bechtold et al. (2004). The solution containing GSH and GSSG was extracted in ice-cold $1 \mathrm{~mL}$ of $\mathrm{HCl}(0.1 \mathrm{M})$ from $0.2 \mathrm{~g}$ fresh wheat leaves which were ground in liquid nitrogen and the extract was kept on ice for $30 \mathrm{~min}$. The supernatant was prepared to measure the glutathione content by HPLC after centrifugation $(20,000 \times g, 10 \mathrm{~min})$. In order to measure the total GSH, dithiothreitol (DTT) was used for the reduction of GSSG to GSG. The absorbance was scanned at $210 \mathrm{~nm}$ by an Agilent 1260 system (Agilent Technologies, USA).

Thylakoid isolation, gel electrophoresis, and immunodetection: Thylakoid membranes were isolated from wheat leaves under dim light with $10 \mathrm{mM} \mathrm{NaF}$ (Chen et al. 2016b). The Chl concentration of the thylakoid protein extracts was calculated as proposed previously by Porra 
et al. (1989). Isolated thylakoid proteins were separated by $15 \%$ SDS-PAGE and subsequently transferred to the PVDF membrane (Immobilone, Millipore, Darmstadt, Germany). Thylakoid proteins were detected with specific antibodies against the D1, D2, CP43, PsbS, Lhcb1-3, Lhcb4 (CP29), Lhcb5 (CP26), Lhcb6 (CP24) and Lhca1-4 proteins, which were purchased from Agrisera Comp. (Umea, Sweden). Detection of phosphoproteins was performed with the anti-phospho/threonine antibody (Cell Signaling, Ipswich, MA, USA). The ECL reagent ( $G E$ Healthcare) was applied for detection of the immunoblots. The Quantity-One software (Bio-Rad Comp., Hercules, CA, USA) was used for analysis of signal amplitudes of the immunoblots.

Gene expression analysis: Total RNA from wheat seedlings was extracted by using the Plant RNA Isolation Kit (Invitrogen, USA) and treated with RNase-free DNase (2212, Takara) according to the manufacturer's instructions. For qRT-PCR analysis, specific primers of eight stress-responsive genes (TaMYB73, TaABC1, TaOPR1, TaASR1, TaWRKY44, TaWRKY2, TaWRKY19, and TaCIPK29) were synthesized (Table 2S, supplement). Stress-associated genes in wheat plants were analyzed by qRT-PCR according to the method of Zhang et al. (2015). SYBR Premix Ex Taq ${ }^{\mathrm{TM}}$ II Master (TaKaRa, Japan) was used for quantitative gene expression assays. Based on the comparative threshold cycle method $\left(2^{-\Delta \Delta C} \mathrm{~T}\right.$ method $)$
(Livak and Schmittgen 2001), relative gene expression levels were showed. A fragment of wheat actin gene (AB181991) was used as a positive control.

Statistical analysis: All data were presented as the mean values \pm standard deviation (SD). For each measurement, at least four independent replicates were carried out. Statistical analysis was performed using SPSS Statistics 19.0 software (IBM, Chicago, IL), and the comparison was done using Duncan's multiplication range test. Different letters above the columns of figures indicated to be statistically significant among treatments when $P<0.05$.

\section{Results}

Changes in symptoms, Chl content, and RWC under three environmental stresses: The symptoms of wheat under three environmental stresses were shown in Fig. $1 \mathrm{~A}$. Compared with control plants, wheat leaves showed mild wilting under osmotic stress for $1 \mathrm{~d}$. However, $3 \mathrm{~d}$ of osmotic stress resulted in the obvious wilting. In addition, we found that high light and salt stress did not lead to the significant changes in symptoms of plants compared with the control. Consistently, RWC significantly decreased by 25.0 and $42.1 \%$ under osmotic stress for 1 and $3 \mathrm{~d}$, respectively, compared with the control (Fig. 1S $A$ ). These results suggest that osmotic stress probably resulted in the severest damage to wheat as compared to high light and salt stress.

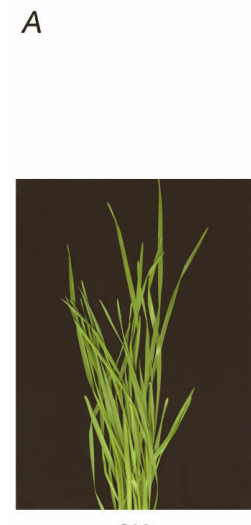

CK

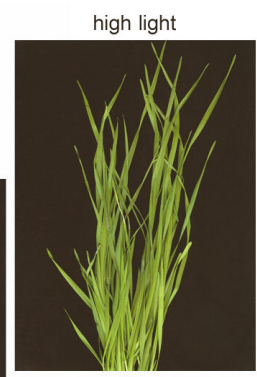

$1 \mathrm{~h}$

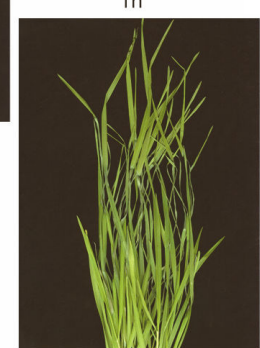

3h

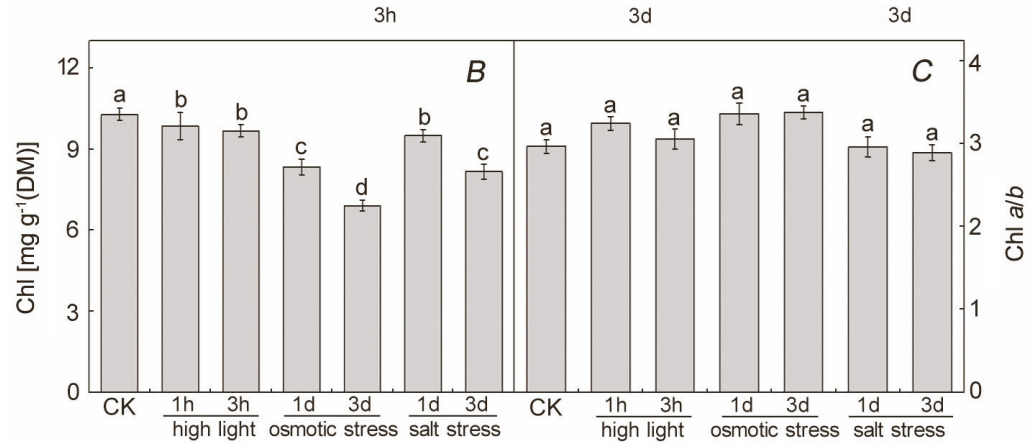

osmotic stress

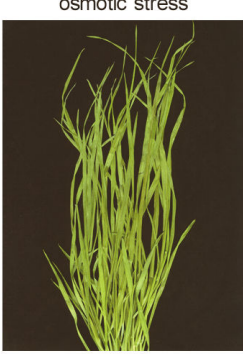

$1 d$

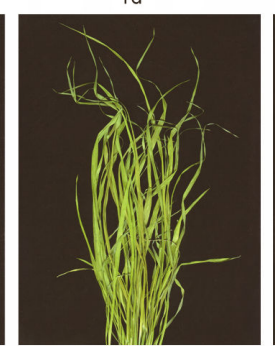

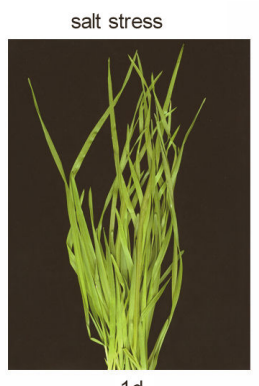

$1 \mathrm{~d}$

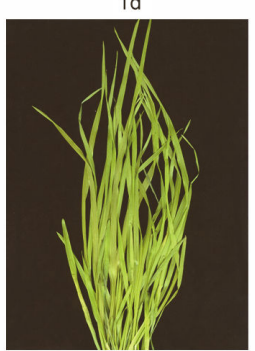

Fig. 1. Phenotype (A), chlorophyll content $(\mathrm{Chl})(B)$, and chlorophyll $a / b$ ratio $(\mathrm{Chl} a / b)$ $(C)$ in wheat plants under three environmental stresses. Bars represent standard deviations from four independent biological replicates $(n=4)$. Different letters indicate significant differences $(P<0.05)$ according to Duncan's multiplication range test. $\mathrm{CK}$, nonstressed wheat plants; high light for 1 and $3 \mathrm{~h}$; osmotic stress for 1 and $3 \mathrm{~d}$; salt stress for 1 and $3 \mathrm{~d}$. 
Although the decrease in Chl content is a common phenomenon under environmental stresses (Chen et al. 2017), Fig. $1 B$ shows no significant differences in $\mathrm{Chl} a / b$ under all three environmental stresses compared with the control (Fig. 1C), while the total Chl content exhibited a significant decline (Fig. 1B). Compared to high light, osmotic stress led to the most obvious decline in Chl content, suggesting that wheat suffered severe damage.

Total proteins, proline, and soluble sugar content: The content of total proteins was significantly reduced under high light for $3 \mathrm{~h}$, osmotic stress for 1 and $3 \mathrm{~d}$, and salt stress for $3 \mathrm{~d}$ compared with that observed in the control (Fig. 1SB). Contrarily, contents of proline and soluble sugars significantly increased in the leaves of wheat under three environmental stresses (Fig. $1 \mathrm{~S} C, D$ ). Under severe stress, the highest increase in proline and soluble sugar contents was observed under osmotic stress compared with the control.

ROS, lipid peroxidation, and cell death: To investigate differences in oxidative damage under three different stresses, the contents of the two major ROS species were analyzed. Compared with control, the different changes in ROS accumulation were observed (Fig. 2A,B). Both $\mathrm{O}_{2}{ }^{-}$ and $\mathrm{H}_{2} \mathrm{O}_{2}$ were significantly accumulated in the leaves of wheat under three stressful conditions relative to the control plants. Furthermore, the accumulation of $\mathrm{O}_{2}{ }^{--}$and $\mathrm{H}_{2} \mathrm{O}_{2}$ was more apparent under osmotic stress than that of high light and salt stress. In order to confirm further these results, contents of $\mathrm{O}_{2}{ }^{-}$and $\mathrm{H}_{2} \mathrm{O}_{2}$ in leaves were measured under three environmental stresses (Fig. 2S $A, B$ ). Similarly, the most obvious increase in the contents of ROS was found under osmotic stress. Contents of $\mathrm{O}_{2}{ }^{-}$and $\mathrm{H}_{2} \mathrm{O}_{2}$ under osmotic stress for $3 \mathrm{~d}$ increased significantly by 175.9 and $169.8 \%$, respectively. The degree of oxidative damages in wheat exposed to three environmental stresses was evaluated by the content of MDA and EL. The three stresses significantly increased the MDA content and EL compared with the control (Fig. 2SC,D). However, $3 \mathrm{~d}$ of osmotic stress and salt stress resulted in more significant increase in MDA content and EL than that of high light relative to the control.

In order to detect further the effect of high ROS accumulation on wheat seedlings, the cell death was investigated in wheat leaves exposed to three environmental stresses. More intensive blue stains were observed in leaves exposed to three environmental stresses, indicating that obvious cell death occurred under such stressful conditions in wheat (Fig. 2C,D). Furthermore, we found that osmotic stress and salt stress resulted in a more serious cell death than that of high light. The results obtained from ROS accumulation and cell death suggest that wheat suffered severer oxidative damage from osmotic stress compared to high light and salt stress.

Enzymatic and nonenzymatic antioxidant activities: The discrepancy regarding ROS accumulation led us to further explore antioxidant defense systems in wheat. Under high light, the activities of all antioxidant enzymes except for CAT significantly increased compared with the control plants (Fig. 3). However, high light for $3 \mathrm{~h}$ resulted in the significant decrease in the activities of these enzymes compared to high light for $1 \mathrm{~h}$. The activities of six antioxidant enzymes showed the significant increase and decrease under osmotic stress for 1 and $3 \mathrm{~h}$ compared with the control, respectively (Fig. 3). Under salt stress, the activities of POD, CAT, APX, GR, and GPX showed a detectable increase relative to the control (Fig. 3). These results indicated that wheat probably had different redox regulation under different environmental stresses.

Some important antioxidants, such as AsA/DHA and GSSG/GSH, were further studied. Concentrations of AsA and GSH greatly decreased, while contents of DHA and GSSG significantly increased under three environmental stresses compared with the control, especially under the severer stresses (Fig. 3S, supplement). However, osmotic stress resulted in the most obvious changes in contents of antioxidants among those three stresses.

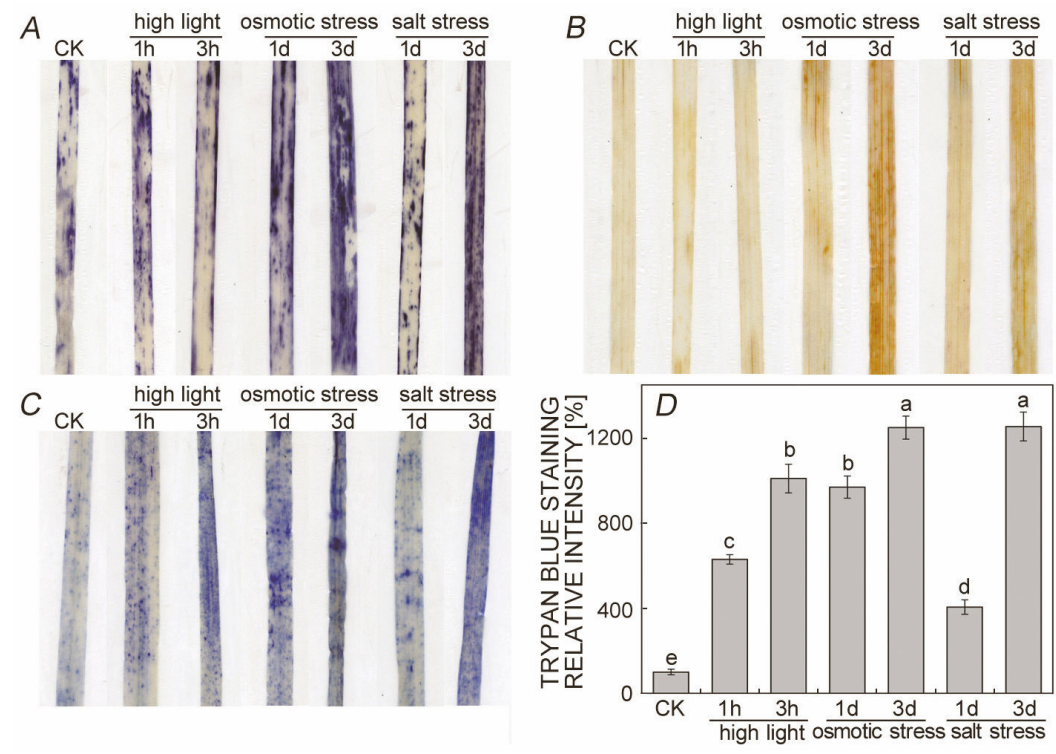

Fig. 2. Reactive oxygen species (ROS) and cell death in wheat plants under three environmental stresses. Histochemical assays for superoxide anion radicals $\left(\mathrm{O}_{2}{ }^{-}\right)$and hydrogen peroxide $\left(\mathrm{H}_{2} \mathrm{O}_{2}\right)$ by $\mathrm{NBT}(A)$ and $\mathrm{DAB}(B)$ staining, respectively. Degree of cell death was obtained from trypan blue staining $(C)$. The relative intensity of trypan blue staining was analyzed $(D)$. Bars represent standard deviations from four independent biological replicates $(n=4)$. Different letters indicate significant differences $(P<0.05)$ according to Duncan's multiplication range test. $\mathrm{CK}$, nonstressed wheat plants; high light for 1 and $3 \mathrm{~h}$; osmotic stress for 1 and $3 \mathrm{~d}$; salt stress for 1 and $3 \mathrm{~d}$. 


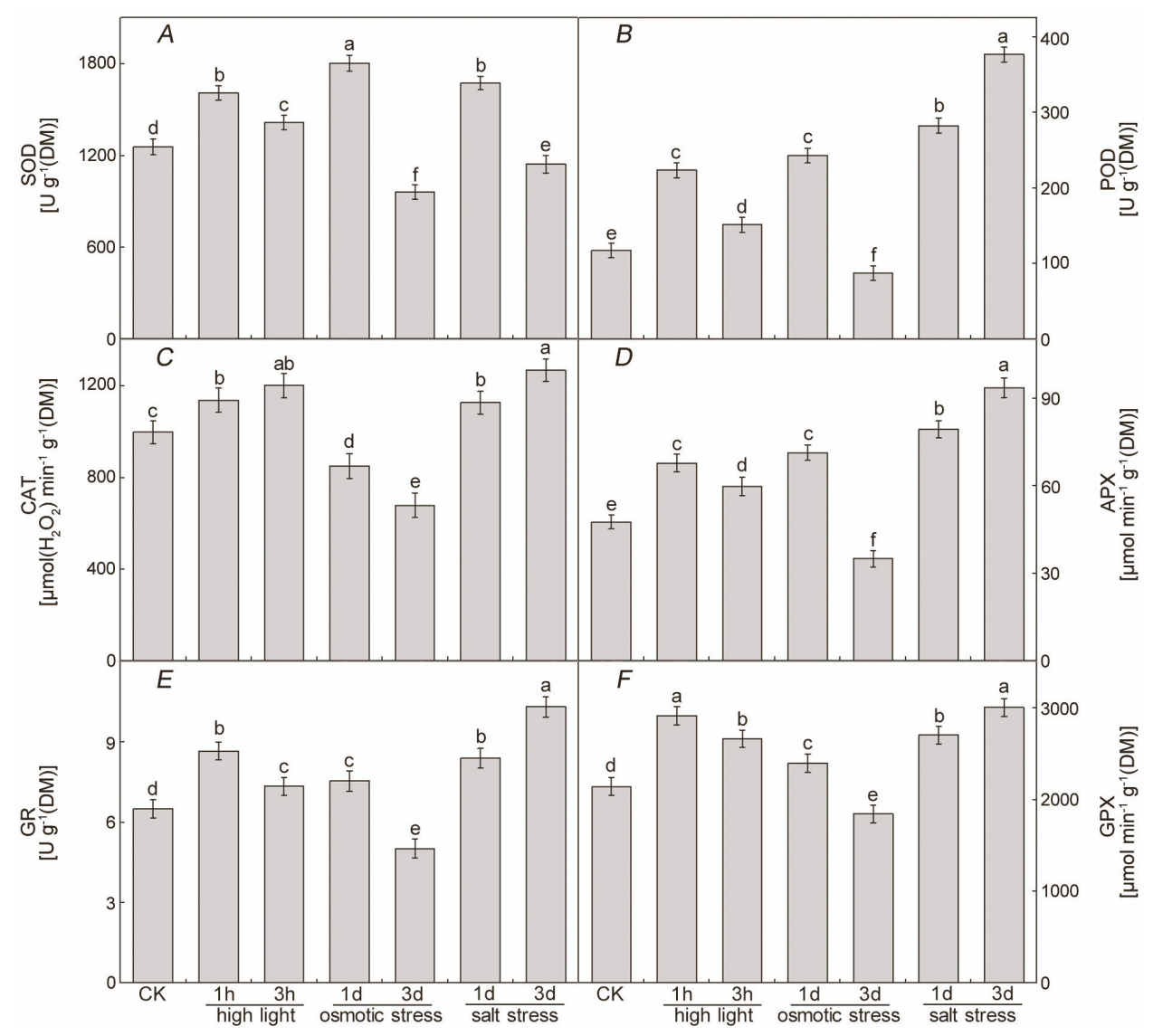

Fig. 3. The activities of superoxide dismutase (SOD) $(A)$, peroxidase $(\mathrm{POD})(B)$, catalase $(\mathrm{CAT})(C)$, ascorbate peroxidase $(\mathrm{APX})(D)$, glutathione reductase $(\mathrm{GR})(E)$, and glutathione peroxidase $(\mathrm{GPX})(F)$ in wheat plants under three environmental stresses. Bars represent standard deviations from four independent biological replicates $(n=4)$. Different letters indicate significant differences $(P<0.05)$ according to Duncan's multiplication range test. CK, nonstressed wheat plants; high light for 1 and $3 \mathrm{~h}$; osmotic stress for 1 and $3 \mathrm{~d}$; salt stress for 1 and $3 \mathrm{~d}$.

Photosynthesis: Only $3 \mathrm{~d}$ of osmotic stress decreased significantly the value of the maximal quantum yield of PSII photochemistry $\left(\mathrm{F}_{\mathrm{v}} / \mathrm{F}_{\mathrm{m}}\right)$ compared with the control (Fig. 4A). Furthermore, compared with the control, a sharp decrease in the quantum yield of PSII electron transport $\left(\Phi_{\mathrm{PSII}}\right)$ was found under all three stresses (Fig. $4 B$ ). In contrast, the nonphotochemical quenching coefficient $\left(\mathrm{q}_{\mathrm{N}}\right)$ showed a significant increase under high light for $3 \mathrm{~h}$, and osmotic stress and salt stress for 1 and $3 \mathrm{~d}$ (Fig. 4A). In addition, the values of the photochemical quenching coefficient $\left(\mathrm{q}_{\mathrm{P}}\right)$ decreased obviously under high light for $3 \mathrm{~h}$, osmotic stress for 1 and $3 \mathrm{~d}$, and salt stress for $3 \mathrm{~d}$ (Fig. 4D)

Compared with the control, $1 \mathrm{~d}$ of osmotic stress resulted in the rapid increase in NPQ (Fig. 5). However, induction of NPQ under other stresses, except for salt stress for $1 \mathrm{~d}$, was lower and arrived at lower amplitudes relative to the control, especially for osmotic stress for $3 \mathrm{~d}$. Moreover, dark recovery of NPQ was different between those three stresses. Except for high light, the value of NPQ under osmotic stress and salt stress relaxed to the similar level of that of the control in the dark, which was nearly equal to the control. We also determined the capacity of State I to State II transition under three environmental stresses (Fig. 4S, supplement). Compared with the control, a higher decrease in fluorescence was observed under high light and osmotic stress when illumination was provided with red light or far-red light. However, there was no obvious difference in state transition between salt stress and the control.

Compared with the control, three environmental stresses led to the significant decrease in $P_{\mathrm{N}}, E$, and $g_{\mathrm{s}}$, while the obvious increase of $C_{\mathrm{i}}$ was observed (Fig. 5S, supplement). However, the most significant decrease or increase in gas-exchange parameters was found under osmotic stress compared with the control, especially osmotic stress for $3 \mathrm{~d}$.

Although PSI quantum yield $\left(\Phi_{\mathrm{PSI}}\right)$, the quantum yield of nonphotochemical energy dissipation of PSI reaction centers due to an acceptor side limitation $\left(\Phi_{\mathrm{NA}}\right)$, and the quantum yield of nonphotochemical energy dissipation in PSI reaction centers due to donor-side limitation $\left(\Phi_{\mathrm{ND}}\right)$ showed no significant difference between three environmental stresses and the control in all light intensities, a significant decrease in the maximal P700 signal $\left(\mathrm{P}_{\mathrm{m}}\right)$ was observed under high light for $3 \mathrm{~h}$, and osmotic and salt stress for $3 \mathrm{~d}$ (Fig. 6S, supplement). 

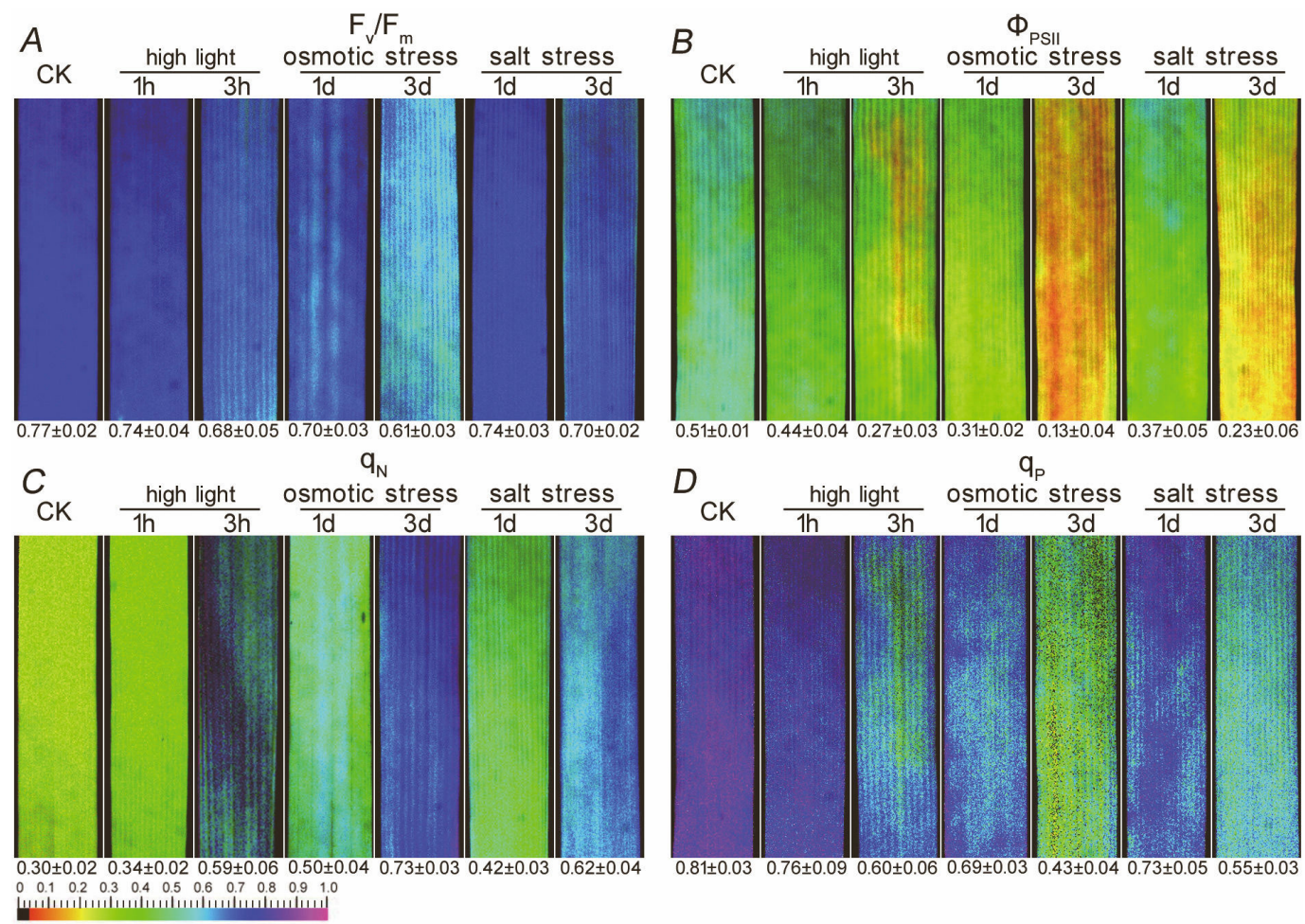

Fig. 4. Chlorophyll fluorescence parameters in wheat plants under three environmental stresses: maximum efficiency of PSII photochemistry, $\mathrm{F}_{\mathrm{v}} / \mathrm{F}_{\mathrm{m}}(A)$; quantum yield of PSII electron transport, $\Phi_{\mathrm{PSII}}(B)$; nonphotochemical quenching coefficient, $\mathrm{q}_{\mathrm{N}}(C)$; and photochemical quenching coefficient, $\mathrm{q}_{\mathrm{P}}(D)$. Quantitative data $( \pm \mathrm{SD})$ are shown below the individual fluorescence images. $\mathrm{CK}$, nonstressed wheat plants; high light for 1 and $3 \mathrm{~h}$; osmotic stress for 1 and $3 \mathrm{~d}$; salt stress for 1 and $3 \mathrm{~d}$.

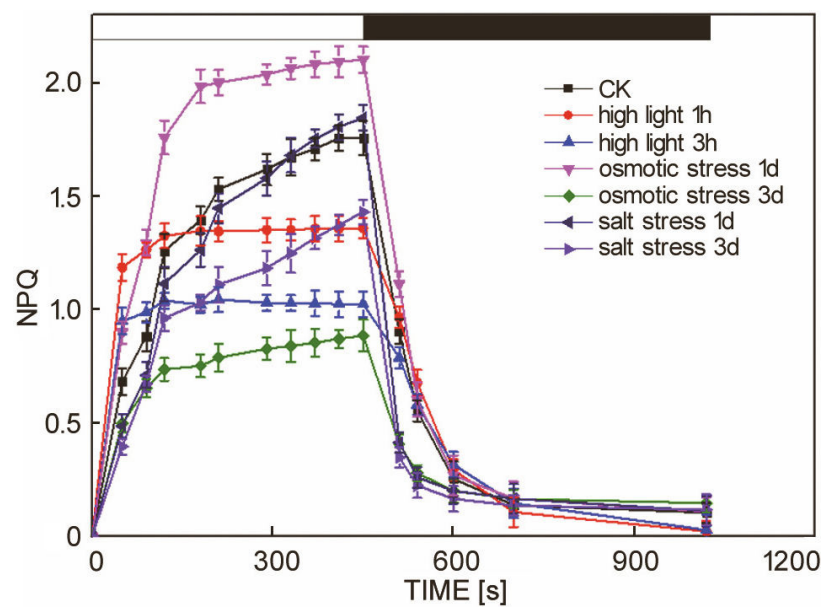

Fig. 5. The kinetics of nonphotochemical quenching (NPQ) of wheat plants illuminated with $1,000 \mu \mathrm{mol}\left(\right.$ photon) $\mathrm{m}^{-2} \mathrm{~s}^{-1}$ for 10 min with a 15 -min period darkness, as presented by the white and black bars, respectively. Data $( \pm \mathrm{SD})$ show an average of four independent measurements. CK, nonstressed wheat plants; high light for 1 and $3 \mathrm{~h}$; osmotic stress for 1 and $3 \mathrm{~d}$; salt stress for 1 and $3 \mathrm{~d}$.

Thylakoid membrane protein contents and phosphorylation: Compared with the control, three environmental stresses caused a significant decrease in the amount of D1 protein, especially the osmotic stress for $3 \mathrm{~d}$ (Figs. 6A; $7 \mathrm{~S}$, supplement). However, the content of PsbS showed significant increase under three stresses as compared with the control. Interestingly, only high light for $3 \mathrm{~h}$ resulted in the significant increase in the amounts of CP26 and CP24 among three environmental stresses compared with the control (Figs. 6C,7S). Other analyzed thylakoid membrane proteins showed no detectable changes between stressed and the control plants. In addition, the phosphorylated pattern of PSII subunits was also analyzed by phosphoprotein-specific immunoblotting. Although the phosphorylation level of LHCII and CP43 did not exhibitany obvious differences between three environmental stresses and the control, the accumulation of phosphorylated-D1 (P-D1) and P-D2 markedly increased under high light, salt stress, and osmotic stress for 1d (Fig. 7). However, $3 \mathrm{~d}$ of osmotic stress resulted in the obvious decrease in the phosphorylation level of D1 and D2 relative to the other stresses (Fig. 7).

Expression of stress-associated genes: Obvious differences in the expression of eight stress-responsive genes (TaMYB73, TaABC1, TaOPR1, TaASR1, TaWRKY44, TaWRKY2, TaWRKY19, and TaCIPK29) were found under three environmental stresses (Fig. 8). Compared with the control, high light resulted in the significant decrease in the expression of all stress-associated genes except for TaASR1 (Fig. 8). However, high light for $3 \mathrm{~h}$ significantly increased the expression of TaABC1, TaOPR1, TaWRKY44, TaWRKY2, and TaCIPK29 compared to high light for $1 \mathrm{~h}$ (Fig. 8B,C,E,F,H). In addition, the expression of TaMYB73, 


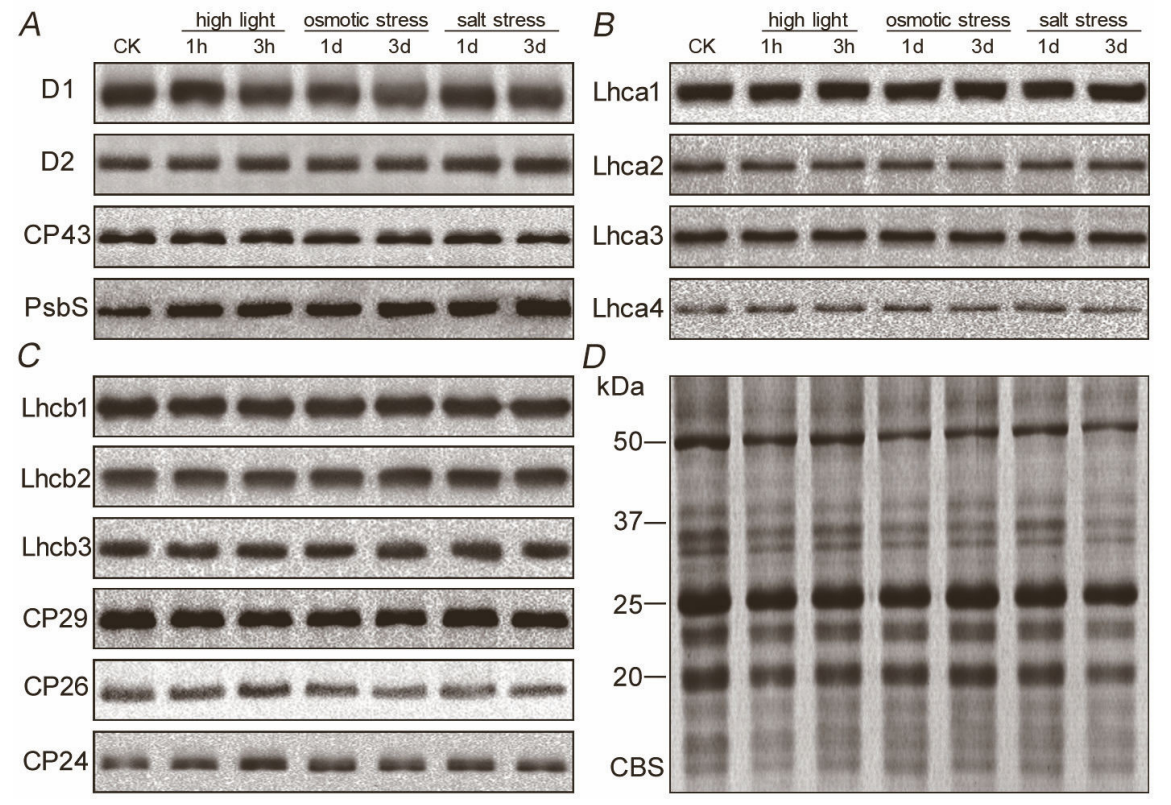

Fig. 6. Immunoblotting of thylakoid membrane proteins of wheat plants under three environmental stresses. Thylakoid proteins were immunoblotted with specific antibodies against representative photosystem I (PSI) and photosystem II (PSII) proteins. (A) D1, D2, CP43, and PsbS. (B) Lhca1, Lhca2, Lhca3, and Lhca4. (C) Lhcb1, Lhcb2, Lhcb3, CP29, CP26, and CP24. The results from Coomassie Blue staining (CBS) of SDS-PAGE were presented $(D)$. Total chlorophyll $(1 \mu \mathrm{g})$ was loaded into each electrophoretic lane. CK, nonstressed wheat plants; high light for 1 and $3 \mathrm{~h}$; osmotic stress for 1 and $3 \mathrm{~d}$; salt stress for 1 and $3 \mathrm{~d}$.
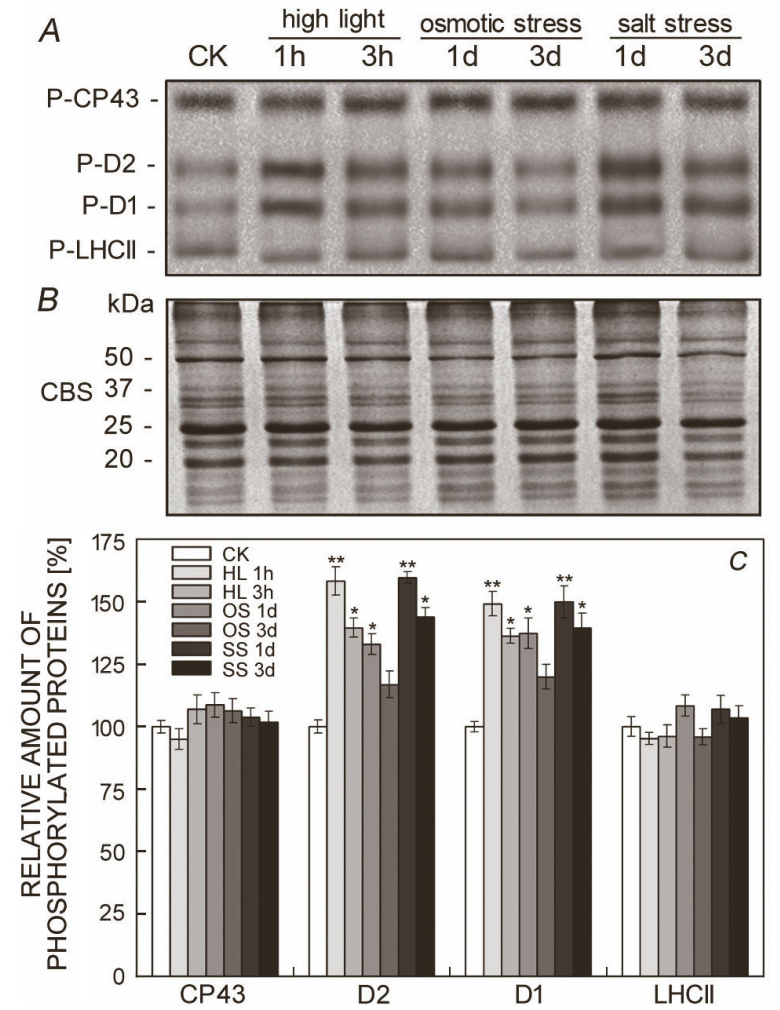

Fig. 7. Phosphorylation of PSII proteins in wheat plants under three environmental stresses. Immunoblotting of PSII proteins was carried out using anti-phosphothreonine antibodies $(A)$. $1 \mu \mathrm{g}$ of total chlorophyll was loaded into each electrophoretic lane. The results from Coomassie Blue staining (CBS) of SDS-PAGE $(B)$. Quantification of protein phosphorylation $(C)$. Data are shown relative to the amount of respective CK $(100 \%)$. Values are means \pm SD from four independent biological replicates $(n=4)$. Asterisks show statistically significant differences when $P<0.05$ (Duncan's multiplication range test). CK, nonstressed wheat plants; high light (HL) for 1 and $3 \mathrm{~h}$; osmotic stress (OS) for 1 and $3 \mathrm{~d}$; salt stress (SS) for 1 and $3 \mathrm{~d}$.
TaABC1, TaOPR1, and TaCIPK29 under osmotic stress substantially increased compared with the control, whereas the expression of TaASR1 and TaWRKY19 was obviously upregulated (Fig. 8D,G), especially for osmotic stress for $3 \mathrm{~h}$. However, we found that salt stress significantly downregulated the expression of eight stress-associated genes relative to the control. Thus, these results indicated that wheat plants can response to different environmental stresses through regulating the expression of different stress-responsive genes.

\section{Discussion}

Environmental stresses usually lead to large losses in crop yield in the world (Boyer 1982). However, many crops have evolved various mechanisms to cope with the adverse environments. Many studies have also indicated that different plant species can alleviate the oxidative damage and thereby improve photosynthesis through redox regulations under environmental stresses (Rizhsky et al. 2004, Chen et al. 2011, 2017). In this study, we investigated the different oxidative stress and redox regulations in wheat under three environmental stresses.

Changes in water status and subsequent plant wilting are a common phenomenon under environmental stresses, especially drought (Zhang et al. 2013, Chen et al. 2016a). Our results showed that obvious wilting and decline in RWC occurred in wheat under osmotic stress. The reason might be the lower osmotic adjustment of plants under osmotic stress, induced by PEG than other environmental stresses (Ranjbarfordoei et al. 2002). Our previous studies indicated that the reduction in photosynthetic pigments is a common phenomenon under stressful conditions (Chen et al. 2016a, 2017). In the present experiment, three environmental stresses reduced the pigment content in wheat. The reduction of $\mathrm{Chl}$ content can be attributed to the enhancement of Chl degradation (Chen et al. 2017). Furthermore, our study showed that osmotic stress mar- 


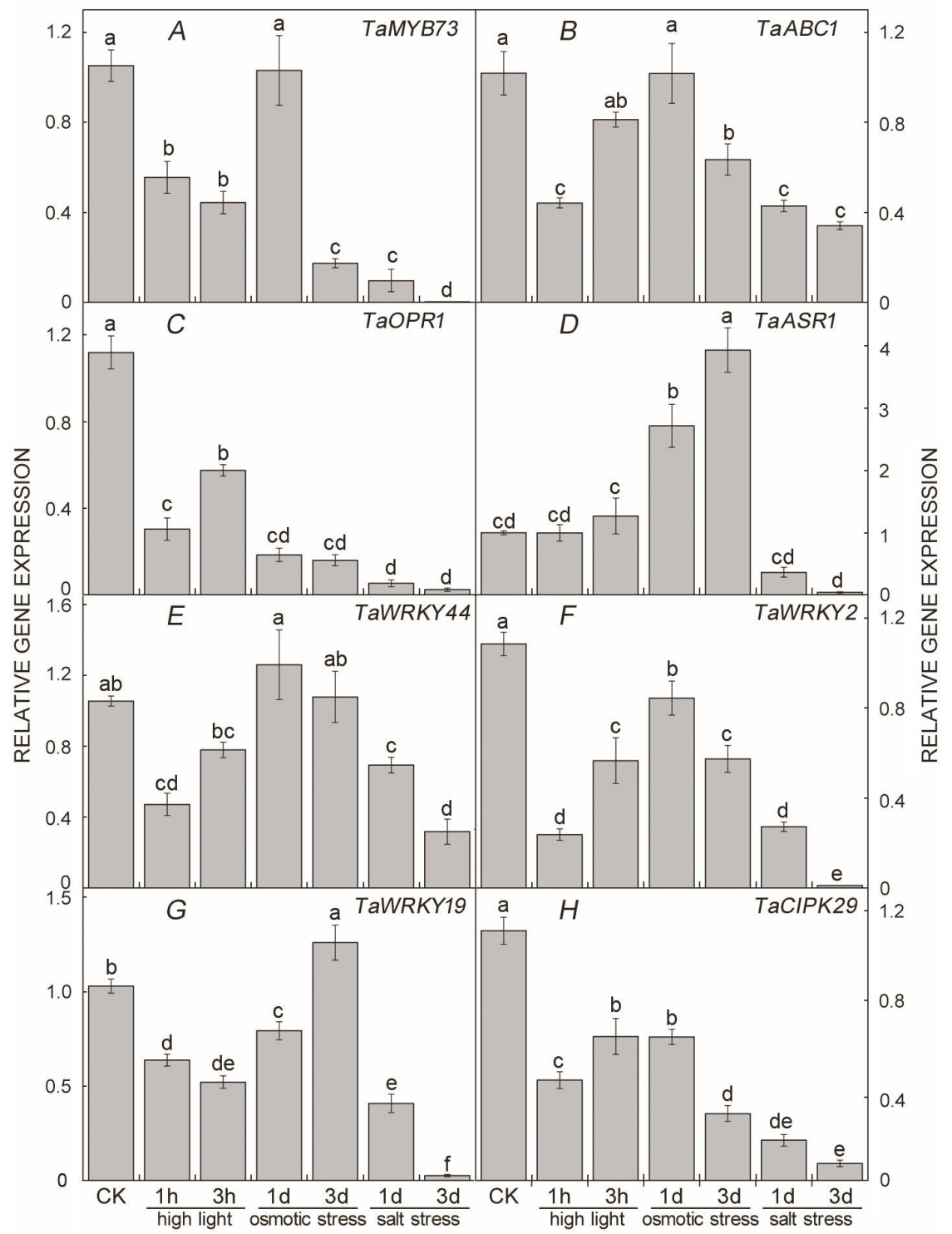

Fig. 8. Expression of eight stressresponsive genes in wheat plants under three environmental stresses. Gene expression levels of TaMYB73 $\begin{array}{llll}(A), \text { TaABC1 } & (B), \text { TaOPR1 } & (C),\end{array}$ TaASR1 (D), TaWRKY44 (E), TaWRKY2 $(F)$, TaWRKY19 $(G)$ and TaCIPK29 $(H)$ were analyzed by qRT-PCR. The wheat Actin gene was used as a positive control. Bars represent standard deviations from four independent biological replicates $(n=4)$. Different letters indicate significant differences $(P<0.05)$ according to Duncan's multiplication range test. CK, nonstressed wheat plants; high light for 1 and $3 \mathrm{~h}$; osmotic stress for 1 and $3 \mathrm{~d}$; salt stress for 1 and $3 \mathrm{~d}$. CK, nonstressed wheat plants; high light for 1 and $3 \mathrm{~h}$; osmotic stress for 1 and $3 \mathrm{~d}$; salt stress for 1 and $3 \mathrm{~d}$. kedly decreased Chl content relative to high light and salt stress. This finding indicated that wheat plants suffered more severe damage under osmotic stress.

Two important osmotic regulators, soluble sugars and proline, usually accumulate to prevent water loss under abiotic stress in many plants (Xu and Huang 2010, Chen et al. 2017). Our results showed that the obvious increase in two osmotic regulators occurred under three environmental stresses. In addition, more pronounced contents of proline and soluble sugars were found in wheat under severe osmotic stress. Osmotic regulators provide some means of maintaining cellular turgor in order to balance the rapid declines of tissue water potential (Bowne et al. 2012). Therefore, our findings suggested that plants could alleviate the damage to the cell by adjusting the osmotic regulators under different environmental stresses.

Environmental stresses can result in the excessive generation and accumulation of ROS and subsequently cause the oxidative stress and cell death in many plants (Singh and Singhal 2001, Chen et al. 2017, 2018).
Our results showed that three environmental stresses remarkably induced ROS accumulation and cell death in wheat leaves. In addition, it has been shown that the large accumulation of ROS may damage the integrity of cell membranes under environmental stresses in plants (Smirnoff 1993, Chen et al. 2018). MDA and EL are regarded as two important indicators of the redox status (Zhang et al. 2014). In accordance with the data obtained from ROS accumulation, we found that MDA and EL were largely accumulated in wheat plants under three environmental stresses. Furthermore, our results showed that ROS accumulation, the content of MDA and EL, and cell death were more severe under osmotic stress. However, high light resulted in the relative low ROS accumulation and cell death, particularly under severe stressful conditions. Therefore, these findings implied that wheat plants have a different redox regulation under different environmental stresses.

To maintain redox homeostasis in vivo and alleviate oxidative stress under environmental stresses, an effective 
antioxidant defense system containing enzymatic and nonenzymatic antioxidants usually plays an important role in protecting plants against oxidative damage. Some reports found that the activities of antioxidant enzymes showed different changes in different plants under stressful conditions (Bartoli et al. 1999, Chaitanya et al. 2002, Chen et al. 2018). In the present study, we found that the activities of almost all antioxidant enzymes markedly increased under three mild environmental stresses. This is probably because wheat plants can alleviate the oxidative damage from ROS accumulation effectively by activating antioxidant enzyme system rapidly (Chen et al. 2017). However, the activities of antioxidant enzymes showed different changes under severe stresses. The decrease in the activities of several antioxidant enzymes under $3 \mathrm{~h}$ of high light relative to $1 \mathrm{~h}$ of high light should contribute to photoinhibition under long-term high light. Under salt stress for $3 \mathrm{~d}$, almost all antioxidant enzymes still maintained high activities, suggesting that wheat plants can low the generation of ROS effectively by improving the antioxidant enzyme activities under severe salt stress. However, $3 \mathrm{~d}$ of osmotic stress resulted in the significant decline in the activities of all antioxidant enzymes. This may be because plants suffered the disruption in antioxidant enzymatic system under severe osmotic stress. In addition, the ASA-GSH cycle also plays an important role in direct quenching of ROS and control of the redox state of photosynthesis (Noctor and Foyer 1998). In the present study, these differences in antioxidant enzyme activities were further identified by the concentrations of AsA/DHA and GSH/GSSG under three severe environmental stresses.

Chl fluorescence is usually considered as a noninvasive probe in studying photosynthetic performance under various environmental stresses in plant species (Murata et al. 2007, Chen et al. 2017). $\mathrm{F}_{\mathrm{v}} / \mathrm{F}_{\mathrm{m}}$ is the maximal PSII quantum yield and is rather insensitive to environmental stresses (Sperdouli and Moustakas 2012, Chen et al. 2016a, 2018). In the present study, the significant changes in $F_{v} / F_{m}$ were found under severe osmotic stress. The reason was probably because the reaction center of PSII suffered serious damage under severe stressful condition. In addition, the significant decrease of $\Phi_{\mathrm{PSII}}$ and $\mathrm{q}_{\mathrm{P}}$ was observed under heavy environmental stresses, suggesting a reduction in the photochemical efficiency of the PSII (Baker 2008). Gas-exchange parameters are a good indicator for stress tolerance in plants (James et al. 2008). The decrease of photosynthetic capacity was confirmed by low $P_{\mathrm{N}}, g_{\mathrm{s}}$, and $E$ under three environmental stresses, especially for severe osmotic stress.

It is well known that excess light energy is harmlessly dissipated as NPQ, which is the important photoprotection process in photosynthesis. In the present study, the low level of NPQ under three environmental stresses indicated that wheat plants did not effectively dissipate excess light energy by heat and thereby decrease the efficiency of photochemical reactions of photosynthesis (Gilmore 1997, de Bianchi et al. 2008). The results were further confirmed by the value of $\mathrm{q}_{\mathrm{N}}$, which is the most sensitive indicator in evaluating the earlier environmental stress. Furthermore, state transitions, as another important photoprotective mechanism, play a key regulatory role in the process of energy dissipation by binding LHCII with PSI or PSII (Allen 1992). Here, our results showed that state transitions of three environmental stresses differed from the control, especially under severe osmotic stress. The reason is probably because LHCII cannot migrate effectively between PSI and PSII under severe environmental stresses. Therefore, our results suggested that wheat plants dissipate the excessive light energy through the different photoprotective mechanism under different environmental stresses.

Although PSII is more vulnerable to environmental stresses than PSI, the damage of PSI is a more severe problem due to its slower recovery (Sonoike 2011). A previous study indicated that the oxidized $\mathrm{P}_{700}{ }^{+}$acted as a remover of excessive reducing power to protect PSI from photoinhibition (de Bianchi et al. 2011). In this present study, a significant decrease in $\mathrm{P}_{\mathrm{m}}$ was found under three severe environmental stresses. It is probably due to a permanent reduction of PSI donor side to protect PSI against the oxidative damage.

Our recent studies indicated that several PSII proteins, mainly including D1, PsbS, CP26, and CP24 showed different response to environmental stresses in different plants (Chen et al. 2016a, 2017, 2018). In this study, the severe osmotic stress resulted in the high decline in D1 protein relative to high light and salt stress, suggesting that severe environmental stresses damaged PSII reaction center and subsequently hampered turnover of D1 protein. Our previous study indicated that the content of the PsbS protein increased under long-term drought stress in Arabidopsis thaliana, which induced the formation of NPQ (Chen et al. 2016a). In the present study, the significant increase in the content of PsbS under three environmental stresses may occur because it plays an important role as a kinetic modulator of the energy dissipation process (Ware et al. 2014). In addition, CP24 and CP26 are also involved in the energy dissipation in plants (Kovács et al. 2006). Our recent study indicated that the CP26 and CP24 proteins remarkably increased in wheat under heat and high light combined stress (Chen et al. 2017). Our results showed that only severe high light stress resulted in the increase in CP26 and CP24. Therefore, the upregulation of CP24 and CP26 is probably necessary for the dissipation of excess light energy under long-term high light stress. Numerous earlier reports have shown that reversible phosphorylation of PSII proteins is mainly involved in the PSII-repair cycle under environmental stresses (Fristedt et al. 2009, Tikkanen and Aro 2012). In the present study, we found that the levels ofD 1 and D2 protein phosphorylation significantly increased under three environmental stresses except for severe osmotic stress, suggesting that the rapid and strong phosphorylation of PSII reaction center proteins was necessary for the PSII-repair cycle under environmental stresses in wheat plants (Chen et al. 2017). Therefore, our results indicated that wheat plants had different mechanisms to respond to different environmental stresses by regulating the levels of PSII proteins and phosphorylated proteins.

Many previous studies have indicated that over- 
expressing the wheat stress-responsive genes, such as TaMYB73, TaABC1, TaOPR1, TaASR1, TaWRKY44, TaWRKY2, TaWRKY19, and TaCIPK29, can improve environmental stress tolerance in transgenic plants (Wang et al. 2011, He et al. 2012, Niu et al. 2012, Deng et al. 2013, Dong et al. 2013, Hu et al. 2013, Wang et al. 2015). In the present study, we measured the expression of eight marker genes involved in stress response by qRT-PCR in wheat plants under three environmental stresses. Previous research showed that TaMYB73, TaOPR1, and TaCIPK29 are involved in salt stress (He et al. 2012, Deng et al. 2013, Dong et al. 2013). Our results indicated that salt stress led to the most obvious decrease in the expression of TaMYB73, TaOPR1, and TaCIPK29 after three environmental stresses, suggesting that these genes might be involved in salt-stress tolerance. TaASR 1, as a transcription factor gene in wheat, could improve the osmotic stress tolerance by activating antioxidant system genes in transgenic tobacco (Hu et al. 2013). In the present study, we found that only osmotic stress significantly upregulated the levels of TaASR1, indicating that TaASR1 may play an important regulatory role in improving osmotic stress tolerance in wheat. It has been shown that overexpression of TaABC1, TaWRKY44, TaWRKY2, and TaWRKY19 could confer abiotic stress tolerance in transgenic plants (Wang et al. 2011, 2015; Niu et al. 2012). The present study showed that severe salt stress resulted in the remarkable decrease in the expression of these genes. The reason may be that these genes are sensitive to salt stress. The obvious increase in the levels of TaABC1, TaWRKY44, and TaWRKY2 under high light for $3 \mathrm{~h}$ was probably because they were acting under long-term high light stress. In addition, the high transcript levels of TaABC1, TaWRKY44, TaWRKY2, and TaWRKY19 under osmotic stress suggest that these genes were possibly involved in osmotic stress tolerance, especially TaWRKY19.

Conclusions: In the present study, we found that plants could adjust the redox status in vivo by the different changes in the antioxidant defense system, regulating different stress-responsive genes, and PSII protein phosphorylation under different environmental stresses. The results showed that osmotic stress and high light caused the highest and lowest oxidative damage to wheat plants among three environmental stresses, respectively. Under salt stress, rapid responses of POD, APX, and GR were detected. Moreover, eight stress-associated genes showed different expression levels under three environmental stresses, especially the significant expression of TaASR1 under osmotic stress. In addition, analyses of thylakoid proteins indicated that the levels and phosphorylation of PSII reaction center proteins showed the different changes in wheat plants under three environmental stresses. However, the receptors and response pathways of plants under different environmental stresses still need to be further investigated.

\section{References}

Adir N., Zer H., Shochat S., Ohad I.: Photoinhibition - a historical perspective. - Photosynth. Res. 76: 343-370, 2003.
Allen J.F.: Protein phosphorylation in regulation of photosynthesis. - BBA-Bioenergetics 1098: 275-335, 1992.

Arnon D.I.: Copper enzymes in isolated chloroplasts. Polyphenoloxidase in Beta vulgaris. - Plant Physiol. 24: 267-272, 1949.

Baker N.R.: Chlorophyll fluorescence: a probe of photosynthesis in vivo. - Annu. Rev. Plant Biol. 59: 89-113, 2008.

Barnabás B., Jäger K., Fehér A.: The effect of drought and heat stress on reproductive processes in cereals. - Plant Cell Environ. 31: 11-38, 2008.

Bartoli C.G., Simontacchi M., Tambussi E. et al.: Drought and watering-dependent oxidative stress: effect on antioxidant content in Triticum aestivum L. leaves. - J. Exp. Bot. 50: 375-383, 1999.

Bates L.S., Waldren R.P., Teare I.D.: Rapid determination of free proline for water-stress studies. - Plant Soil 39: 205-207, 1973.

Bechtold U., Murphy D.J., Mullineaux P.M.: Arabidopsis peptide methionine sulfoxide reductase 2 prevents cellular oxidative damage in long nights. - Plant Cell 16: 908-919, 2004.

Beers Jr. R.F., Sizer I.W.: A spectrophotometric method for measuring the breakdown of hydrogen peroxide by catalase. J. Biol. Chem. 195: 133-140, 1952.

Bowne J.B., Erwin T.A., Juttner J. et al.: Drought responses of leaf tissues from wheat cultivars of differing drought tolerance at the metabolite level. - Mol. Plant 5: 418-429, 2012.

Boyer J.S.: Plant productivity and environment. - Science 218: 443-448, 1982.

Chaitanya K.V., Sundar D., Masilamani S., Reddy A.R.: Variation in heat stress-induced antioxidant enzyme activities among three mulberry cultivars. - Plant Growth Regul. 36: 175-180, 2002.

Chaves M.M.: Effects of water deficits on carbon assimilation. J. Exp. Bot. 42: 1-16, 1991.

Chen X.Y., Li W., Lu Q.T. et al.: The xanthophyll cycle and antioxidative defense system are enhanced in the wheat hybrid subjected to high light stress. - J. Plant Physiol. 168: 1828-1836, 2011.

Chen Y.E., Cui J.M., Su Y.Q. et al.: Influence of stripe rust infection on the photosynthetic characteristics and antioxidant system of susceptible and resistant wheat cultivars at the adult plant stage. - Front. Plant Sci. 6: 779, 2015.

Chen Y.E., Liu W.J., Su Y.Q. et al.: Different response of photosystem II to short and long-term drought stress in Arabidopsis thaliana. - Physiol. Plantarum 158: 225-235, 2016 a.

Chen Y.E., Mao J.J., Sun L.Q. et al.: Exogenous melatonin enhances salt stress tolerance in maize seedlings by improving antioxidant and photosynthetic capacity. - Physiol. Plantarum 164: 349-363, 2018.

Chen Y.E., Yuan S., Schröder W.P.: Comparison of methods for extracting thylakoid membranes of Arabidopsis plants. Physiol. Plantarum 156: 3-12, 2016 b.

Chen Y.E., Zhang C.M., Su Y.Q. et al.: Responses of photosystem II and antioxidative systems to high light and high temperature co-stress in wheat. - Environ. Exp. Bot. 135: 45-55, 2017.

Cossani C.M., Reynolds M.P.: Physiological traits for improving heat tolerance in wheat. - Plant Physiol. 160: 1710-1718, 2012.

de Bianchi S., Betterle N., Kouril R. et al:: Arabidopsis mutants deleted in the light-harvesting protein Lhcb4 have a disrupted photosystem II macrostructure and are defective in photoprotection. - Plant Cell 23: 2659-2679, 2011.

de Bianchi S., Dall'Osto L., Tognon G. et al:: Minor antenna proteins CP24 and CP26 affect the interactions between photosystem II subunits and the electron transport rate in grana membranes of Arabidopsis. - Plant Cell 20: 1012-1028, 2008. 
Deng X., Hu W., Wei S. et al.: TaCIPK29, a CBL-interacting protein kinase gene from wheat, confers salt stress tolerance in transgenic tobacco. - PLoS ONE 8: e69881, 2013.

Dong W., Wang M., Xu F. et al.: Wheat oxophytodienoate reductase gene $T a O P R_{l}$ confers salinity tolerance via enhancement of abscisic acid signaling and reactive oxygen species scavenging. - Plant Physiol. 161: 1217-1228, 2013.

Farooq M., Bramley H., Palta J.A. et al.: Heat stress in wheat during reproductive and grain-filling phases. - Crit. Rev. Plant Sci. 30: 491-507, 2011.

Flowers T.J.: Improving crop salt tolerance. - J. Exp. Bot. 55: 307-319, 2004

Foyer C.H., Halliwell B.: The presence of glutathione and glutathione reductase in chloroplasts: A proposed role in ascorbic acid metabolism. - Planta 133: 21-25, 1976.

Fristedt R., Willig A., Granath P. et al.: Phosphorylation of photosystem II controls functional macroscopic folding of plant photosynthetic membranes in Arabidopsis. - Plant Cell 21: 3950-3964, 2009

Giannopolitis C.N., Ries S.K.: Superoxide dismutases: I. Occurrence in higher plants. - Plant Physiol. 59: 309-314, 1977.

Gill S.S., Tuteja N.: Reactive oxygen species and antioxidant machinery in abiotic stress tolerance in crop plants. - Plant Physiol. Bioch. 48: 909-930, 2010.

Gilmore A.M.: Mechanistic aspects of xanthophyll cycledependent photoprotection in higher plant chloroplast and leaves. - Physiol. Plantarum 99: 197-209, 1997.

Grassi G., Magnani F.: Stomatal, mesophyll conductance and biochemical limitations to photosynthesis as affected by drought and leaf ontogeny in ash and oak trees. - Plant Cell Environ. 28: 834-849, 2005.

Havir E.A., McHale N.A.: Biochemical and developmental characterization of multiple forms of catalase in tobacco leaves. - Plant Physiol. 84: 450-455, 1987.

He Y., Li W., Lv J. et al.: Ectopic expression of a wheat MYB transcription factor gene, TaMYB73, improves salinity stress tolerance in Arabidopsis thaliana. - J. Exp. Bot. 63: 1511$1522,2012$.

Hu W., Huang C., Deng X. et al.: TaASR1, a transcription factor gene in wheat, confers drought stress tolerance in transgenic tobacco. - Plant Cell Environ. 36: 1449-1464, 2013.

James R.A., von Caemmerer S., Condon A.G. (Tony) et al.: Genetic variation in tolerance to the osmotic stress component of salinity stress in durum wheat. - Funct. Plant Biol. 35: 111-123, 2008.

Klughammer C., Schreiber U.: An improved method, using saturating light pulses, for the determination of photosystem I quantum yield via $\mathrm{P} 700^{+}$-absorbance changes at $830 \mathrm{~nm}$. Planta 192: 261-268, 1994.

Kovács L., Damkjær J., Kereïche S. et al.: Lack of the lightharvesting complex CP24 affects the structure and function of the grana membranes of higher plant chloroplasts. - Plant Cell 18: 3106-3120, 2006.

Livak K.J., Schmittgen T.D.: Analysis of relative gene expression data using real-time quantitative PCR and the $2^{-\Delta \Delta C}$ T method. Methods 25: 402-408, 2001.

Loggini B., Scartazza A., Brugnoli E., Navari-Izzo F.: Antioxidative defense system, pigment composition, and photosynthetic efficiency in two wheat cultivars subjected to drought. - Plant Physiol. 119: 1091-1099, 1999.

Lowry O.H., Rosebrough N.J., Farr A.L., Randall R.J.: Protein measurement with the Folin phenol reagent. - J. Biol. Chem. 193: 265-275, 1951.

Maxwell K., Johnson G.N.: Chlorophyll fluorescence a practical guide. - J. Exp. Bot. 51: 659-668, 2000.

Mbarki S., Sytar O., Živčák M. et al.: Anthocyanins of coloured wheat genotypes in specific response to salt stress. - Molecules 23: $1518,2018$.

Mehler A.H.: Studies on reactions of illuminated chloroplasts. II. Stimulation and inhibition of the reaction with molecular oxygen. - Arch. Biochem. Biophys. 34: 339-351, 1951.

Mittler R., Vanderauwera S., Gollery M., Van Breusegem F.: Reactive oxygen gene network of plants. - Trends Plant Sci. 9: 490-498, 2004.

Mittler R.: Oxidative stress, antioxidants and stress tolerance. Trends Plant Sci. 7: 405-410, 2002.

Murata N., Takahashi S., Nishiyama Y., Allakhverdiev S.I.: Photoinhibition of photosystem II under environmental stress. BBA-Bioenergetics 1767: 414-421, 2007.

Nakano Y., Asada K.: Hydrogen peroxide is scavenged by ascorbate-specific peroxidase in spinach chloroplasts. - Plant Cell Physiol. 22: 867-880, 1981

Niu C.F., Wei W., Zhou Q.Y. et al.: Wheat WRKY genes TaWRKY2 and TaWRKY19 regulate abiotic stress tolerance in transgenic Arabidopsis plants. - Plant Cell Environ. 35: 11561170, 2012.

Niyogi K.K.: Safety valves for photosynthesis. - Curr. Opin. Plant Biol. 3: 455-460, 2000.

Noctor G., Foyer C.H.: Ascorbate and glutathione: keeping active oxygen under control. - Annu. Rev. Plant Phys. 49: 249-279, 1998.

Okuda T., Matsuda Y., Yamanaka A., Sagisaka S.: Abrupt increase in the level of hydrogen peroxide in leaves of winter wheat is caused by cold treatment. - Plant Physiol. 97: 12651267, 1991.

Pietrzykowska M., Suorsa M., Semchonok D.A. et al.: The light-harvesting chlorophyll $a / b$ binding proteins Lhcb1 and Lhcb2 play complementary roles during state transitions in Arabidopsis. - Plant Cell 26: 3646-3660, 2014.

Porra R.J., Thompson W.A., Kriedemann P.E.: Determination of accurate extinction coefficients and simultaneous equations for assaying chlorophylls $a$ and $b$ extracted with four different solvents: verification of the concentration of chlorophyll standards by atomic absorption spectroscopy. - BBABioenergetics 975: 384-394, 1989.

Powles S.B.: Photoinhibition of photosynthesis induced by visible light. - Ann. Rev. Plant Physio. 35: 15-44, 1984.

Ramakrishna A., Ravishankar G.A.: Influence of abiotic stress signals on secondary metabolites in plants. - Plant Signal. Behav. 6: 1720-1731, 2011.

Ranjbarfordoei A., Samson R., Lemeur R., Van Damme P.: Effects of osmotic drought stress induced by a combination of $\mathrm{NaCl}$ and polyethylene glycol on leaf water status, photosynthetic gas exchange, and water use efficiency of Pistacia khinjuk and P. mutica. - Photosynthetica 40: 165-169, 2002.

Rico C.M., Hong J., Morales M.I. et al.: Effect of cerium oxide nanoparticles on rice: a study involving the antioxidant defense system and in vivo fluorescence imaging. - Environ. Sci. Technol. 47: 5635-5642, 2013.

Rizhsky L., Liang H.J., Shuman J. et al.: When defense pathways collide: the response of Arabidopsis to a combination of drought and heat stress. - Plant Physiol. 134: 1683-1696, 2004.

Shah F., Huang J., Cui K. et al.: Impact of high-temperature stress on rice plant and its traits related to tolerance. - J. Agr. Sci. 149: 545-556, 2011.

Singh A.K., Singhal G.S.: Effect of irradiance on the thermal stability of thylakoid membrane isolated from acclimated wheat leaves. - Photosynthetica 39: 23-27, 2001.

Smirnoff N.: The role of active oxygen in the response of plants to water deficit and desiccation. - New Phytol. 125: 27-58, 1993. 
Sonoike K.: Photoinhibition of photosystem I. - Physiol. Plantarum 142: 56-64, 2011.

Sperdouli I., Moustakas M.: Interaction of proline, sugars, and anthocyanins during photosynthetic acclimation of Arabidopsis thaliana to drought stress. - J. Plant Physiol. 169: 577-585, 2012.

Sytar O., Živčák M., Brücková K. et al.: Shift in accumulation of flavonoids and phenolic acids in lettuce attributable to changes in ultraviolet radiation and temperature. - Sci. Hortic.-Amsterdam 239: 193-204, 2018.

Thomas T.A.: An automated procedure for the determination of soluble carbohydrates in herbage. - J. Sci. Food Agr. 28: 639-642, 1977.

Tikkanen M., Aro E.M.: Thylakoid protein phosphorylation in dynamic regulation of photosystem II in higher plants. BBA-Bioenergetics 1817: 232-238, 2012.

van Wees S.: Phenotypic analysis of Arabidopsis mutants: trypan blue stain for fungi, oomycetes, and dead plant cells. - CSH Protoc. 3: pdb.prot4982, 2008.

Verma S., Mishra S.N.: Putrescine alleviation of growth in salt stressed Brassica juncea by inducing antioxidative defense system. - J. Plant Physiol. 162: 669-677, 2005.

Wang C., Jing R., Mao X. et al.: TaABC1, a member of the activity of $b c_{1}$ complex protein kinase family from common wheat, confers enhanced tolerance to abiotic stresses in Arabidopsis. -
J. Exp. Bot. 62: 1299-1311, 2011.

Wang X., Zeng J., Li Y. et al.: Expression of TaWRKY44, a wheat WRKY gene, in transgenic tobacco confers multiple abiotic stress tolerances. - Front. Plant Sci. 6: 615, 2015.

Ware M.A., Belgio E., Ruban A.V.: Comparison of the protective effectiveness of NPQ in Arabidopsis plants deficient in PsbS protein and zeaxanthin. - J. Exp. Bot. 66: 1259-1270, 2014.

Xu C.P., Huang, B. R.: Differential proteomic responses to water stress induced by PEG in two creeping bentgrass cultivars differing in stress tolerance. - J. Plant Physiol. 167: 14771485,2010

Xu J., Zhu Y.Y., Ge Q. et al.: Comparative physiological responses of Solanum nigrum and Solanum torvum to cadmium stress. New Phytol. 196: 125-138, 2012.

Zhang H.J., Zhang N., Yang R.C. et al.: Melatonin promotes seed germination under high salinity by regulating antioxidant systems, $\mathrm{ABA}$ and $\mathrm{GA}_{4}$ interaction in cucumber (Cucumis sativus L.). - J. Pineal Res. 57: 269-279, 2014.

Zhang W.E., Wang F., Pan X.J. et al.: Antioxidant enzymes and photosynthetic responses to drought stress of three Canna edulis cultivars. - Korean J. Hortic. Sci. 31: 677-686, 2013.

Zhang Z., Chen J., Su Y. et al.: TaLHY, a 1R-MYB transcription factor, plays an important role in disease resistance against stripe rust fungus and ear heading in wheat. - PLoS ONE 10: e0127723, 2015.

(C) The authors. This is an open access article distributed under the terms of the Creative Commons BY-NC-ND Licence. 